\title{
Exilio y multiculturalidad: perspectivas de exilio y viaje en un relato de la autora saudí Raja Alem
}

\author{
Milagros NUIN MONREAL \\ Departamento de Estudios Árabes e Islámicos \\ Universidad Complutense de Madrid \\ milagros.nuin@filol.ucm.es
}

\section{RESUMEN}

El presente artículo analiza brevemente la situación actual de la novela árabe en Arabia Saudí, y después se centra en la novela de Raja Alem, titulada Sitr (Ocultación), que fue publicada en 2005, desde una perspectiva que mezcla el viaje o el exilio interior de la protagonista con imágenes propias de la globalización en un mundo sin fronteras.

Palabras clave: exilio interior, novela árabe, novelista saudí, multiculturalidad, posmodernismo, globalización, Arabia Saudí.

Exile and multiculturality: Perspectives of exile and travel in a story of Raja Alem, a Saudi novelist

\begin{abstract}
This papper examines concisely the present situation of the arabic novel in Saudi Arabia, in order to focus on the novel by Raja Alem, Sitr (Concealment), that was published in 2005. It was treated from a perspective that mixes travel and interior exile in the spirit of the main character with some images characteristic of globalization in a world without frontiers.
\end{abstract}

Key words: interior exile, arabic novel, Saudi novelist, multiculturality, postmodernism, globalization, Saudi Arabia.

\section{INTRODUCCIÓN}

La novela árabe ha recorrido desde su nacimiento hasta la actualidad un trecho muy breve si lo comparamos con los recorridos de la novela en otros ámbitos lin- 
güísticos. Los estudiosos egipcios de la narrativa árabe (Darray 1999: 143; Usfur 1999: 20) coinciden en afirmar que las primeras novelas surgieron de la pluma de autores egipcios y libaneses en las décadas de los años veinte y treinta del siglo XX. No obstante, esta opinión ha encontrado la oposición de quienes se han empeñado en considerar las obras de finales del siglo XIX como novelas, y la de quienes, más radicales, no ven que haya existido novela árabe como tal antes de que aparecieran las primeras obras de Naguib Mahfuz en los años cuarenta (Gubayr 2000: 16).

Ha habido otros países de esta zona de Oriente Medio, como es el caso de los de la Península Arábiga y del Reino de Arabia Saudí, en particular, que han sido incluso más tardíos a la hora de producir sus obras, y en ellos se da también una etapa de preparación que discurre, en este caso, entre 1930 y 1959, y en la que destacan varios autores cuyos nombres no se mencionan, pues su importancia es relativa. Es ésta una época en la que predominan obras de corte romántico e historicista.

Por ello, habrá que esperar hasta los años sesenta y setenta del siglo XX, y ello debido a razones históricas y socioculturales, para que vean la luz las primeras obras dignas de recibir la denominación de novelas. En la segunda mitad del siglo XX, sobre todo entre 1960 y 1980, es cuando discurre una segunda etapa creativa en el devenir de la narrativa en Arabia Saudí. Hay un predominio casi absoluto de escritores varones, entre los que sobresale una figura de talla gigantesca, Abd al-Rahmán Munif (1933-2004), con una impresionante producción novelística repartida entre la Península Arábiga e Iraq ${ }^{1}$. En esta etapa aparecen obras de corte realista y, en muchos casos, autobiográfico.

Desde 1980 hasta la actualidad, se inicia una tercera etapa de producción novelística en la que se integran obras de autores anteriores con las de otros más jóvenes, algunos de ellos periodistas, nacidos en los años cincuenta y sesenta, con varias novelas interesantes, en las últimas de las cuales se analiza la cuestión del terrorismo islamista desde un punto de vista que tiene pretensiones de objetividad. Es en la década de los sesenta cuando nacen varias escritoras que se forman en las facultades dedicadas a las mujeres de las universidades saudíes, que se habían fundado, por iniciativa real, en los años cincuenta y sesenta.

A finales del siglo XX y comienzos del XXI se da un momento propicio para que se publiquen las obras de esta generación de autores en la que la presencia femenina es realmente destacable. Asimismo, es necesario subrayar que en ocasiones se solventan las posibles incompatibilidades de los contenidos de estas novelas con el régimen político y la sociedad saudíes recurriendo a editoriales transfronterizas situadas en Líbano, Marruecos o Egipto.

\section{SOBRE LAAUTORA}

En este panorama destaca la autora Raja Alem, que nació en la década de los sesenta en la ciudad santa de La Meca, situada en el Reino de Arabia Saudí, en el

${ }^{1}$ Parte de su obra está traducida al castellano. 
seno de una familia que se podría considerar como perteneciente a la clase media de la ciudad (su hermana Shadia es una conocida pintora). Su padre ostentaba un cargo relacionado con a extracción y reparto del agua del pozo sagrado de Zemzem, y en su casa se adquirió la primera radio que llegó a la ciudad de La Meca. La abierta mentalidad de sus progenitores, a pesar de que su madre era analfabeta, propició que los hijos de la familia, con independencia de su sexo, obtuvieran una formación universitaria. Se licenció en Literatura Inglesa por la Universidad del Rey Abdelaziz en Yidda y en 1985 obtuvo el premio Ibn Tufayl del Instituto Hispano-Árabe de Cultura por su primera novela, titulada Cuatro Cero (Arbaa Sifr). Para ampliar información sobre Raja Alem y su obra se puede consultar el artículo publicado sobre su novela Játim (Nuin Monreal 2008: 127-139).

Ha publicado hasta la actualidad obras de teatro, ensayos, relatos destinados a niños, cuentos cortos y nueve novelas. Ha recibido también numerosos premios como reconocimiento a su sólida labor literaria, y parte de su obra se ha traducido a otras lenguas, al castellano, al inglés y al francés. Una de sus novelas, titulada Játim, que también está traducida al castellano, fue elegida el 5 de junio de 2002 para ser distribuida gratuitamente en todo el mundo árabe junto con los periódicos de mayor tirada, dentro del programa patrocinado por la UNESCO para el fomento de la lectura "Un libro en un periódico".

La trayectoria de la autora a través de sus ocho primeras novelas se podría perfilar como la de un recorrido que ha optado desde el inicio por indagar en el pasado, aunque no sea un pasado marcado por unos parámetros estrictamente temporales. A Raja Alem le interesa más un tiempo relativamente indefinido en el que sobresalen unos valores que se podrían calificar de tradicionales, vistos desde la óptica de una mujer culta que indaga, profundiza y sugiere. En este sentido, el lenguaje que utiliza tiene unas dimensiones poéticas dotadas de unas características muy personales. Por otro lado, el mundo de Raja Alem es profundamente musulmán, como se encarga ella de repetir cuando le preguntan por sus raíces y por el origen de la inspiración de sus historias. En todo el conjunto de su obra se pueden rastrear elementos que pertenecen a la mística musulmana, al sufismo. Hay que señalar también que Raja ha nacido en La Meca, una ciudad que es centro espiritual del mundo musulmán, lugar donde se concentran los lugares santos más importantes del islam. Estos elementos, La Meca como centro del mundo, un lugar al que acuden al año miles de personas procedentes de todo el planeta, están presentes en la mayor parte de sus obras.

\section{SITR (OCULTAMIENTO): IMÁGENES DE EXILIO INTERIOR Y DE VIAJE SUMADAS A POSMODERNISMO Y GLOBALIZACIÓN}

En 2005 salió a la luz la última de las nueve novelas de Raja Alem, y en ella la autora da un giro radical a los que habían sido sus intereses en sus novelas anteriores. Deja de lado el mundo de las tradiciones orales, historias y mitos de La Meca y el Nayd para centrarse en el mundo contemporáneo, aunque, pese a ello, sigue fiel a su forma de escribir, un estilo en el que la sugerencia es el valor primordial. 
Esta obra ha recibido valoraciones muy positivas por parte de la crítica árabe y también críticas encarnizadas procedentes de supuestos lectores en distintas páginas de internet; también una fetua de una autoridad religiosa saudí que la ha calificado de herética y degenerada, junto a las de otros autores de su generación.

Sitr (Ocultamiento) es una novela de extensión media, que en su edición árabe cuenta con 262 páginas. Está estructurada como un texto continuado sin división de capítulos. Solamente se separan los diversos párrafos con unos asteriscos. No obstante, es una obra que se lee con avidez, pues ofrece una visión del mundo contemporáneo que la autora considera producto de un cruce de culturas lleno de vitalidad. Además, la novela esta construida, en parte, sobre las experiencias personales de la autora, que pasa parte del año en ciudades como París, Londres o Nueva York gracias al aval de su hermano menor, y otra parte del año en Yidda, una ciudad saudí ligeramente más liberal que la tradicional y religiosa de La Meca.

El lugar es muy importante en esta obra, y las descripciones se mezclan con reflexiones e impresiones de los personajes, marcando un contrapunto a algunos de ellos, como en el párrafo que se cita a continuación:

Tomó las maletas y las colocó cuidadosamente en el asiento trasero. La hizo sentarse a su lado mientras cruzaban las calles de Riad. Riad es una ciudad que no ha terminado de convertirse en realidad; se halla a medio camino entre la arena del desierto y el aduar, entre el ser humano y la fiera. Su cuerpo se compone de los miembros de una gacela que de tanto correr se han diseminado en enormes extensiones de desierto. Una gacela que ha galopado durante siete décadas y que, al darse la vuelta para recoger sus miembros, ha hallado una ciudad perseguida por cazadores que han construido elevadas murallas en su camino y en su cuerpo. De tal manera que ya no puede lanzar una mirada fugaz para armonizar sus miembros, el antimonio de sus ojos y la feminidad de su huida.

Hay una feminidad oculta en Riad, de la que el visitante sólo puede percibir un severo recuerdo que oscila entre la arena y la fiera. Es una ciudad cuerpo que ni da la bienvenida ni permite que en ella se albergue el que va de paso.

Pero el cuerpo de Taful es una gacela errante que lee los secretos de la ciudad en su arena. La torre Faysaliya observa la ciudad, y junto a ella se alza la torre del Reino; son éstas dos torres distraídas en un tiempo que sólo permite que las torres se levanten corroídas por el acero y el cristal, trituradas en una harina pastelera de proporciones gigantescas.

Taful se distrajo del ardor procedente del que estaba a su lado contemplando las dos torres; reprimió una sonrisa producida por el mensaje telefónico prohibido que representaba al reino saudí como un cuerpo del revés con las piernas por alto mientras la torre Faysaliya lo atravesaba por el centro como si fuera un cohete espacial.

En las dos torres la ciudad respira distraída. A Riad la mima Salmán, mientras que su oxígeno es al-Walid. En el reino saudí el oxígeno ha despojado a la gente de sus muros, con lo que los ojos miran a los ojos, flirtean, aman y acogen. Todo el que siente la extrañeza de la ciudad acude a las torres para establecerse en un rostro o en una mirada.

El reino se relaja dentro del reino vuelto patas arriba en el aire, y la gacela casi completa su encarnación femenina en el cuerpo de la ciudad. El sentido de la 
orientación del beduino avisó a Taful del recorrido que habían hecho a pesar de su desconocimiento de las enormes y enmarañadas vías de la ciudad.

- ¿Estamos en la dirección correcta? La casa de mi hermana se halla en el barrio de las Rosas -dijo ella. (Alem 2005: 42-43)

Como es el caso de otras obras de la narrativa árabe contemporánea, no se encuentran en ella elementos que podrían considerarse exóticos o folklóricos a los ojos del lector occidental. El artículo de $\mathrm{M}^{\mathrm{a}}$ Dolores López Enamorado aporta valiosas observaciones relativas a las condiciones de la novela árabe en relación con el posmodernismo (López Enamorado 2006: 61-76), que huye de todo lo que resulte exótico, con la excepción de las obras que pretenden, y a veces consiguen, alcanzar la categoría de best-sellers. Como se puede comprobar en la obra de J. F. Lyotard (1992: 45-70), el posmodernismo en occidente parece seguir un desarrollo temporal radicalmente distinto al que se contempla en oriente. A este respecto, se puede decir que no hay en esta obra ninguna concesión a la galería. Por contra, estamos ante una novela que puede resultar, tal vez, más "exótica" a los ojos de un lector oriental por lo que tiene de mezcla y mestizaje. Exceptuando las obras de algunas autoras, como la libanesa Hanan al-Sheij, la última obra de la también libanesa Huda Barakat y la egipcia Ahdaf Soueif, no es habitual que en las novelas árabes contemporáneas aparezcan estas mezclas "globalizadoras" de mundos diversos.

El arranque de la novela sitúa al lector en un mundo actual, en el que se dan la mano elementos como el cristal como material constructivo de edificios, una piscina, el uso de internet como medio de comunicación y desahogo de un personaje, etc. Ya no se trata de aquellos elementos arquitectónicos propios de la arquitectura tradicional de La Meca (celosías, construcción en altura, terrazas, etc.) y que aparecían en Játim, con la casa familiar como lugar en el que se centraba una parte importante de la acción de la novela. En esta obra, la autora busca conscientemente una ausencia de lugares concretos. Se vive el lugar como una estación de paso, por lo que aparecen mencionados con frecuencia aeropuertos, aviones y diversos nombres de ciudades. No hay un lugar dominante en el relato, pues la acción se reparte entre la ciudades saudíes de Yidda y Riad, Londres, París, una ciudad de EEUU, Asila en Marruecos, Sharm el-Sheij en Egipto y Beirut. En cada una de estas ciudades se desarrollan hechos que completan el relato como si fueran imágenes complementarias reflejadas en distintos espejos. Es ésta, creo yo, una novela en la que confluyen dos corrientes, el posmodernismo y el universo sin fronteras de la globalización.

Una vez más en la obra de Raja Alem, el título tiene una gran carga simbólica. En este caso ha elegido un término polisémico que se podría traducir al castellano como "ocultamiento". Parece como si la escritora hubiera intentado aproximarse a una sociedad, la suya, que se oculta y protege de sí misma, que vive en un exilio interior buscando en el exterior un contrapeso a sus propias necesidades, en un continuo vaivén que sólo aporta alivios momentáneos. La sociedad saudí vive, por tanto, de espaldas al mundo exterior, muy preocupada por que no se aireen sus problemas, algo que se considera a menudo como una agresión a sus valores más preciados y a la salvaguarda de su intimidad. 
No se trata en este caso de un exilio político, ni de una ausencia del lugar de origen por motivos religiosos o económicos, antes bien se trata de una necesidad imperiosa de respirar otros aires. Creo que en esta obra, a pesar de los numerosos viajes que transcurren en sus páginas, se debe hablar más de literatura de exilio interior que de viaje, en el sentido en que habla R. Jaccard en su obra dedicada a analizar múltiples facetas del viaje interior (Jaccard 1999: 60-63), o lo que analiza J. Kristeva en relación con la melancolía y el exilio interior (Kristeva 1987: 23-38). La protagonista aparece como un personaje exiliado, desplazado del lugar y de su tiempo, alguien que no se muestra conforme con la sociedad en que vive. Este inconformismo la conducirá a contraer su segundo matrimonio en secreto, a espaldas de su madre. Es lo que ocurre cuando se bebe de distintas fuentes. Debido a su formación académica y a la experiencia directa que le han procurado sus viajes, Raja Alem y la protagonista de su novela se encuentran perfectamente cómodas con la rica vida cultural que puede ofrecer al visitante la ciudad de Londres, aunque sea sin renunciar a sus raíces, según demuestra en su novela. Sin ningún ánimo de crítica social, mostrando cierto distanciamiento emocional de los hechos que relata, la autora presenta un amplio abanico de hechos novedosos: la vida de extranjeros europeos y americanos en territorio saudí manteniendo un sistema de vida occidentalizado, el sutil acoso sexual de un poderoso jeque a una de las protagonistas femeninas de la novela, la presión social para que las jóvenes se casen y cumplan con los fines a los que aspiran sus familias, la presión policial impuesta de manera férrea para preservar las buenas costumbres, etc.

Por todo ello, la autora se ha ganado numerosas críticas que se pueden sintetizar en la idea de que ha escandalizado a la sociedad por airear sus problemas, escrúpulos que se mostraron por vez primera, en lo que a la novela árabe en general respecta, en el Egipto de los años veinte. No obstante, la autora da muestras de una libertad interior muy remarcable, a pesar de los innumerables obstáculos que, sin duda, debe encontrar en su vida diaria en Arabia Saudí. No ha intentado ofrecer en su obra un análisis de la sociedad contemporánea desde una perspectiva literaria, puesto que la autora ha huido de un realismo testimonial que se encuentra muy a menudo en otros autores saudíes, con independencia del sexo al que pertenezcan. Junto a ello hay aspectos de la vida saudí contemporánea cuyo registro por escrito resulta para el lector muy novedoso, aunque sea algo corriente en muchos países occidentales, como es la reseña que se efectúa sobre la educación que reciben los más pequeños en una guardería o la descripción del extraño ambiente de una fábrica dedicada a la producción masiva de gambas para la exportación, en la que trabaja uno de los personajes secundarios. Frente a todas estas cuestiones, se sitúa el ambiente libre y multirracial de Londres, donde los protagonistas pueden desarrollar su historia de amor libremente, contando sólo con los límites que se imponen a sí mismos.

El relato se articula, pues, en torno a las experiencias de varias educadoras de una guardería situada en Yidda, amigas y compañeras de trabajo de la protagonista. Y la estrategia narrativa se fundamenta en establecer una contraposición entre deseos incumplidos y realidades. Hay además una total ausencia de referencias religiosas, algo que singulariza esta obra en relación con las anteriores de la autora. 
Por lo que respecta a los personajes, Raja Alem presenta ante los ojos del lector un amplio abanico de posibilidades, desde la protagonista femenina de la novela, una joven saudí llamada Mariam que trabaja en un colegio infantil, hasta sus amigas y compañeras de trabajo, con las que establece unas relaciones de amistad circunstanciales. La protagonista, muy cercana anímicamente a la autora, va marcando el ritmo del relato mediante la exposición de sus propias experiencias vitales y las de sus compañeras. La autora teje un entramado narrativo polifónico y de numerosas perspectivas con un resultado final extremadamente rico. Es interesante contrastar estos términos con las opiniones de teóricos como Rovatti y Vattimo (1996: 4560 ), que reflexionan sobre la posibilidad de un pensamiento difuso, repartido entre varias perspectivas.

La ironía es otro de los elementos a los que recurre con frecuencia la autora, como se puede comprobar en el párrafo siguiente, referido a la maestra beduina, Taful:

-Somos beduinos y ciegos, y mi alma, entre mis costados, es mi primera víctima. Debe soportarme o, si no, terminará en el infierno -afirmó, y siempre estaba dispuesta a hablar de lo que denominaba autocrítica.

-Hay decenas de gafas en nuestra casa y todos participan en su uso. Mi familia no va al médico, nos basta nuestra propia medicina. Mi madre, que es experta en plantas y en remedios naturales, suele repetir que el cuerpo es en sí mismo un médico. Ella es la doctora de todos nosotros, y en primer lugar se encuentra mi pobre padre. Un día le puso unas gotas de un remedio en los ojos, y perdió la vista del derecho; y además le salió en la sien un lunar. Entonces intervino la medicina moderna para proporcionar a mi padre una córnea nueva. De la sala de operaciones salió mi padre beduino, de la tribu de Qahtán, con un ojo azul y otro negro como la noche de Qahtán. Imaginaos nuestra vergüenza por tener a uno de los nuestros medio inglés.

La interrumpieron las carcajadas y siguió diciendo:

-No sé qué puede ver con ese ojo azul, pero, Dios es testigo, se ha iluminado un poco. Ahora el 'no' sale de su boca un segundo después del de mi madre, que es más rápida disparando. América no ha logrado encontrar las armas de destrucción masiva en Iraq porque las mujeres ilustradas de Qahtán, entre ellas mi madre, desde hace mucho tiempo han contrabandeado con ellas escondiéndolas en ese 'no' y las han preparado en sus cabezas y en las de sus hijos para dispararlas sin necesidad de lanzaderas de misiles. Sharon debe estar preparado, pues si ese no cayera sobre Israel lo borraría del mapa. Si vierais cómo lanzan esos noes que no salen de la punta de la lengua, como los nuestros, sino de lo más profundo del paladar $[\ldots]$.

Ayer descubrí que mi padre utiliza las últimas gafas de mi madre y que mi madre utiliza las gafas de mi cuñada y las antiguas de mis hermanas y las de mi abuelo de Hail, y las de una amiga de mi madre que nos avergonzó con sus gafas. Es un festival de gafas y ninguno de nosotros ve. (Alem 2005: 62-63)

De este modo, con el telón de fondo del terrorismo islamista en algunos pasajes aislados, algo habitual en Arabia Saudí en los primeros años del siglo XXI, nos vamos adentrando en la percepción de aspectos de la sociedad saudí actual que la 
autora no ha querido soslayar, como la presión familiar, especialmente por parte de la madre, y social para que la hija de la familia contraiga matrimonio, el matrimonio sin amor, el divorcio, el amor como pasión, etc. Entre los personajes secundarios, la pareja formada por el campeón saudí de musculación y la maestra de origen beduino, Taful, resulta paradigmática a la hora de representar los contrastes y contradicciones que afronta la sociedad saudí de los últimos años. El campeón de culturismo resulta incongruente si lo situamos en su país, pero también lo es en EEUU, país al que emigra con su reciente esposa para encontrar una forma de vida en la que desarrollar sus aficiones.

Salvando el papel desempeñado por la protagonista, que es el personaje más próximo a la autora y que actúa como narradora de lo que sucede a los demás personajes, el personaje secundario más interesante es el desempeñado por la joven beduina mencionada, que representa un contrapunto a la historia del personaje principal. Tenemos, pues, dos personajes distintos, con distintos grados de asimilación de la modernidad, aunque pasan por experiencias similares con resultados distintos. Ambas pasan por matrimonios más o menos fallidos, y por largas estancias en el extranjero. Hay una constante común, que es un continuo deambular de un lugar a otro y una sensación interior de extrañamiento, probablemente para establecer una distancia anímica respecto de hechos y situaciones dolorosas.

Una de las marcas de la autora es el lenguaje que utiliza en esta obra. Al contrario de lo que ha hecho en obras anteriores, como Játim, donde se proponía conscientemente registrar un tipo de lenguaje arcaizante originario de la región saudí de al-Hiyaz, antes de su desaparición, en Sitr muestra una notable preocupación por plasmar de una forma literaria el árabe culto contemporáneo, sin rastro de arcaísmos locales. Es un árabe culto y neutro que podría haberse escrito en cualquier otro país árabe. Raja Alem es, además, una gran maestra en el manejo de los distintos registros que encierra la lengua árabe, por ello los diálogos o reflexiones en los que interviene la maestra beduina recorren todos los matices, desde la ironía hasta la ternura. Esta capacidad de la autora confiere a su obra una gran variedad de tonos y registros relacionados con las distintas personalidades de los personajes.

Por otro lado, Sitr es una obra en la que predomina el lugar sobre el tiempo, pues el tiempo está representado desde el inicio desde una perspectiva alterada. Avanza y retrocede sin previo aviso y a menudo hay que releer párrafos una y otra vez para saber dónde se sitúan los hechos. Hay hechos que se anticipan, como el casamiento secreto de la protagonista, cuyo comportamiento resulta incomprensible para la madre al inicio del relato. La madre, que se muestra desde una óptica represora, se preocupa solamente de que el honor de la familia se mantenga a salvo y de no dar lugar a habladurías.

Sólo se comprende el comportamiento rebelde de la protagonista cuando se lee el final de la novela. En este momento se encuentra esperando ante el juzgado para contraer matrimonio, y se supone que al final, a pesar de las dificultades jurídicas que expone el juez y del atentado terrorista que sucede en las inmediaciones, consigue contraer matrimonio. Todos los sucesos más importantes de la novela se diseminan mediante alusiones extremadamente imprecisas. Fiel a su estilo, el final que plantea la autora es abierto, con imágenes de un totum revolutum causado por el 
atentado. Sólo entonces se comprende que el inicio se ha anticipado parcialmente al desenlace final.

\section{CONCLUSIÓN}

Resulta casi un prodigio que una novela de estas características se haya dado como producto de la pluma de una autora saudí, si tenemos presentes las especiales circunstancias que rodean a este país, que se siente guardián de los Lugares Santos del Islam y también modelo moral para todos los musulmanes del mundo, una pesada carga que resulta muy difícil de asumir. Tal vez las siguientes palabras de María Zambrano (1990: 77) arrojen algo de luz sobre este fenómeno del espíritu humano:

Y así cuando en un instante el corazón se quede del todo quieto se abrirá al par, dándose entero. Es lo que sueña. Como todo lo encerrado, sueña el corazón con escaparse, como todo lo encadenado, desprenderse, aun a costa de desgarrarse. Como todo aquello que contiene algo precioso, con derramarlo de una sola vez. Mientras se sueña así el corazón se reitera y la violencia entonces es su cadena, que más pasivo que nunca arrastra. Va ciego, él es lo único que puede llevar la luz hacia abajo, a los ínferos del ser.

\section{BIBLIOGRAFÍA}

ALEM, Raja (2005): Sitr (Ocultamiento). Casablanca y Beirut: al-Markaz al-Zaqafi alArabi.

DARRAY, Faysal (1999): Nazariyya al-Riwaya wa-l-Riwaya al-Arabiyya. Beirut: Al-Markaz al-Zaqafi al-Arabi.

GUBAYR, Abduh (2000): "Isharat idda ila al-tarij, ishara wahida ila al-mustaqbal". AlHayat, 20, p. 16.

JACCARD, R. (1999): El exilio interior. Barcelona: Azul.

KRISTEVA, J. (1987): Soleil Noir. Repression et mélancolie. Paris: Gallimard.

LÓPEZ ENAMORADO, Ma Dolores (2006): "Literatura árabe y posmodernidad: el juego de la muerte en Duniazad, de May Tilmisani”. Philologia Hispalensis, 20, pp. 61-76.

LYOTARD, J. F. (1992): La condición postmoderna. Barcelona: Planeta Agostini.

NUIN MONREAL, Milagros (2008): "Una novela de Arabia Saudí: Játim, de la autora Raja Alem". Anaquel de Estudios Árabes, vol. 19, pp. 127-139.

ROVATTI, P. A.; y VATTIMO, G. (1996): El pensamiento débil. Madrid: Cátedra.

USFUR, Gáber (1999): Zaman al-Riwaya. El Cairo: al-Hay'a al-Misriyya al-Amma li-lKitab.

ZAMBRANO, María (1990): Claros del bosque. Barcelona: Seix Barral, $3^{a}$ edición. 